\title{
Plasma concentrations of NOX4 are predictive of successful liberation from mechanical ventilation and 28-day mortality in critically ill patients
}

\section{Yoonki Hong}

Kangwon National University https://orcid.org/0000-0002-1607-6777

\section{So Yeong Park}

Hallym University College of Medicine

\section{Seong Ji Woo}

Hallym University College of Medicine

Youngmi Kim

Hallym University College of Medicine

Jae Jun Lee

Hallym University College of Medicine

Ji Young Hong ( $\square$ mdhong@hallym.or.kr)

Hallym University College of Medicine https://orcid.org/0000-0002-3132-7706

\section{Research article}

Keywords: biomarker, mechanical ventilation, mechanical ventilation weaning, NOX4, mortality

Posted Date: November 25th, 2019

DOI: https://doi.org/10.21203/rs.2.17743/v1

License: (1) This work is licensed under a Creative Commons Attribution 4.0 International License. Read Full License 


\section{Abstract}

Background: Nicotinamide adenine dinucleotide phosphate (NADPH) oxidase (NOX) enzymes play important roles in generating reactive oxygen species; in particular, NOX4 plays a distinct role in regulating lung inflammation and apoptosis.

Methods: We determined whether plasma NOX4 level can be used as a prognostic biomarker to guide weaning from mechanical ventilation. Plasma levels of NOX4 were measured at days 1 (NOX4d1) and 7(NOX4d7) after initiation of mechanical ventilation in 184 patients.

Results: Median NOX4d7 levels in patients with extubation failure were significantly higher than those in patients with extubation success $(24.2 \mathrm{ng} / \mathrm{mL}$ vs.15.2 ng/mL, $\mathrm{P}<0.001)$. On multivariate logistic regression, SOFA $\geq 8$ (odds ratio[OR]:2.66; 95\% confidence interval [CI], 1.26-5.59), mechanical ventilation time>11 days (OR: 3.36; 95\% Cl: 1.62-6.99), APACHE score $>21$ (OR, 2.16; 95\% Cl, 1.03-4.52) and NOX4d7>18.2 ng/mL (OR: $3.13,95 \% \mathrm{Cl}: 1.49-6.57$ ) were associated with extubation failure.NOX4d7 level $>18.2 \mathrm{ng} / \mathrm{mL}$ (hazard ratio[HR], 2.17; 95\% Cl, 1.19-3.97), coexisting cancer (HR: 2.22; 95\% Cl, 1.12-4.38), SOFA $\geq 8$ (HR: $2.06 ; 95 \% \mathrm{Cl}, 1.12-3.81)$ and $\mathrm{APACHE}>21$ (HR, 1.82; 95\% Cl, 1.05-3.18) were independently associated with 28-day mortality.

Conclusions: Plasma NOX4 levels may help predict successful liberation from mechanical ventilation and 28-day mortality.

\section{Background}

Extubation failure is associated with high mortality and prolonged ICU stay[1, 2]. Prolonged use of ventilator leads to various complications including ventilator-associated pneumonia, lung barotrauma, and muscle weakness; therefore, it is ideal to wean the patients from the ventilator as soon as possible[3-5].

Several studies have investigatedthe predictors of successful extubation; however, the sensitivity and specificity of these factors have been largely inconsistent[6, 7]. Even $2 \mathrm{~h}$ spontaneous breathing test (SBT), which is thecurrent weaning practice, cannot completely predict successful extubation $[8,9]$. The development ofreadily available point-of-care assays that can help predict weaning success or mortality is of immense clinical relevance.

Nicotinamide adenine dinucleotide phosphate (NADPH) oxidases (NOXs)are enzymes that generate reactive oxygen species (ROS); the role of NOXs has been studied in the context of several lung diseases[10]. NOX4 was shown to be associated with lung inflammation and lung permeability[11]. Oxidative stress plays a significant role in ventilator-and sepsis-induced diaphragm dysfunctions[12, 13]. In septic conditions, NOXs enzymes produced byskeletal muscle fiber were shown to increase ROS production[14,15]. The mechanism of diaphragm weakness involves mitochondrial ROS production 
induced by pathogen-associated molecular patterns and danger-associated molecular patterns, which promotes degradation of sarcomeric proteins via calpains and upregulates the autophagy process[12].

However, the detailed mechanism of NOX4 in ventilator-induced lung inflammation and injury needs to be explored in further studies. Till date, no studies have assessed the association between plasma NOX4 level and successful weaning of mechanically ventilated patients.

The aim of this prospective study was to assess whether plasma NOX4 levels at initiation of mechanical ventilation and serial assessment of plasma NOX4 levels in intubated patients may help predict successful weaning from mechanical ventilation and mortality.

\section{Methods}

\section{Study design and subjects}

The study was conducted at the comprehensive ICU of Chuncheon Sacred Heart Hospital. Patients who were initiated on mechanical ventilation at ICU admission between July 2017 and March 2019 were prospectively recruited and followed up. The exclusion criteria were: 1 ) age $<18$ years; 2 ) initiation of mechanical ventilation 48 hours after ICU admission; 3) presence of neuromuscular disease such as amyotrophic lateral sclerosis; 4) inability to provide informed consent; 5) duration of mechanical ventilation $<7$ days.

Out ofthe542evaluated patients, 358 were excluded because of age criteria $(n=15)$, intubation initiated48 hours after ICU admission ( $(=203)$, presence of neuromuscular disease $(n=5)$, inability to obtain consent $(n=11)$, and short duration of mechanical ventilation $(n=124)$. Thus, 184 patients were enrolled in this study. The study protocol was approved by the institutional review board of the Chuncheon Heart Sacred Hospital (IRB number: 2017-47).

\section{Data collection}

Data pertaining to baseline demographic variables, comorbid diseases, indication for intubation, and clinical variables were collected. Severity of illness at ICU admission was assessed using the Acute Physiology and Chronic Health Evaluation (APACHE II) score and Sequential Organ Failure Assessment (SOFA) score. Type II diabetes, hypertension, chronic renal failure, history of coronary heart disease, heart failure, cerebrovascular disease, and malignancy were evaluated and Charlson comorbidity index was calculated as described elsewhere[16]. Clinical outcomes included weaning success in 3 weeks and 28day mortality.

The ICU attending physicians performed daily weaning assessment after enrollment; patients who qualified the following criteria were considered to have passed the weaning assessment: (1)improvement or resolution of the underlying condition;(2) $\mathrm{PaO}_{2}>60 \mathrm{mmHg}$ at $\mathrm{FiO} 2<0.4$ and positive end-expiratory 
pressure (PEEP) $\leq 5 \mathrm{cmH}_{2}$ Oalong with other clinical criteria; (3) Glascow Coma Scale score >13.All patients who passed weaning assessment underwent 2-hour spontaneous breathing trial (SBT) wherein the patients were placed on spontaneous mode of weaning with low pressure support $\left(8 \mathrm{cmH}_{2} \mathrm{O}\right)$ and zero PEEP with the same $\mathrm{FiO}_{2}(<40 \%)$ for at least $2 \mathrm{hr}$ as. SBT was passed if patients did not develop any of the following signs during the 2 hour-SBT: respiratory rate $>35$ breaths per minute; arterial oxygen saturation $<90 \%$; heart rate $>140$ beats/ $\mathrm{min}$ or systolic blood pressure $>180 \mathrm{mmHg}$ or $<90 \mathrm{mmHg}$; sustained increase or decrease in heart rate $>20 \%$, or signs of respiratory distress such as agitation and diaphoresis.

Weaning failure was defined as either the failure of SBT or the need for reintubation within 48 hours of extubation. Rapid shallow breathing index (RSBI) score was measured when the patients were presumed ready for extubation.

\section{Plasma NOX4 measurement}

Plasma was obtained within 24 hours from initiation of mechanical ventilation (D1) and at day 7 (D7). After supine rest for at least $10 \mathrm{~min}$, fasting blood samples were collected and centrifuged at $2000 \mathrm{rpm}$ for $15 \mathrm{~min}$ at room temperature. Plasma samples were stored at $-80^{\circ} \mathrm{C}$ until further processing and assayed using Human NOX4 (NADPH oxidase 4) ELISA kit (MyBiosource, San Diego CA).

\section{Statistical analysis}

Categorical variables are reported as frequency (percentage) and continuous variables are expressed as median (interquartile range [IQR]). Categorical variables were compared using Chi-square test while continuous variables were compared using Mann-Whitney $U$ test. The non-parametric Wilcoxon signedrank test was used for comparisons between day 1 and day 7 measurements. Patients were stratified into groups according to low or high NOX4 concentrations using the median value for each as the cut-off point.

Multivariate logistic regression analysis was performed to evaluate the risk factors for weaning failure. The effect of plasma NOX4 level was assessed after adjusting for confounding factors and important risk factors. Variables that were associated with $P$ values $<0.1$ in the univariate analysis were incorporated in the multiple logistic regression model. Kaplan-Meier survival curves were constructed for the 28-day period after ICU admission. Cumulative survival rates were compared using the log-rank test; the association between day 7NOX4level and probability of 28-day mortality was assessed using Cox regression analysis.

Statistical analyses were performed using SPSS v. 20.0(SPSS Inc., Chicago, IL, USA) and Prism 5.1 (Graphpad software, La Jolla, CA, USA).Two-tailed $P$ values $<0.05$ were considered indicative of statistical significance. 


\section{Results}

\section{Characteristics ofthe study population}

The demographic and baseline characteristics of the study population are summarized in Table 1. A total of 184 patients were enrolled; of these, only97patients were successfully extubatedwithin3 weeks. Patients with extubation failure were significantly older (76 vs.69years, $P=0.003$ ). The APACHE II score and SOFA score in the failed extubation group were significantly higher than that in the successful extubation group [median (IQR), APACHE:23 (20-28) vs. 19 (15-23); $P<0.001$, SOFA: 9 (7-12) vs 6 (5-9); $P<0.001]$; however, no significant between-group difference was observed with respect to Charlson comorbidity index $[2(1,3)$ vs. $2(1,3), P=0.225]$. The indications for intubation and the proportion of patients with pneumonia at admission were not different between the two groups.

The duration of mechanical ventilation (MV)in the failed extubation group was longer than that in the successful extubation group. The failed extubation group showed higher 28-day mortality and ICU mortality than the successful extubation group. In addition, plasma NOX4 levels on days7 in the failed extubation group were significantly higher than those in the successful extubation group.

\section{NOX4 level and clinical outcome}

NOX4 levels from day 1 and day 7 were analyzed to assess the association with weaning failure. Logistic regression analysis showed that SOFA $\geq 8, \mathrm{APACHE}$ score $>21$, duration of $\mathrm{MV}>11$ days, and day 7 plasma NOX4 levels> $18.2 \mathrm{ng} / \mathrm{mL}$ were independently associated with weaning failure (Table 2).

Higher day 7 NOX4 level was associated with increased odds of weaning failure in both univariate (odds ratio [OR], 3.54; 95\% confidence interval $[\mathrm{Cl}], 1.93-6.51 ; P<0.001)$ and multivariate analyses (OR, 3.13; $95 \% \mathrm{Cl}, 1.49-6.57 ; P=0.003)$. Day 1 NOX4 level was not significantly associated with increased odds of weaning failure.

We disaggregated the study population according to quartiles of day 7 NOX4 levels and assessed their association with success of weaning and 28-day mortality (Figure 1). With increase in NOX4 quartile, the success of weaning tended to decrease and 28-day mortality tended to increase. As shown, each trend was statistically significant.

Kaplan-Meier survival analysis showed that the cumulative survival rate was significantly lower in patients with day 7 NOX4 levels $>18.2 \mathrm{ng} / \mathrm{mL}$ (53.8\% vs.80.2\%, respectively; $P<0.001$ ) (Figure 2).Using Cox regression analysis, the ability of day 7 NOX4leveland several variables to predict mortality was evaluated (Table 3). Coexisting cancer (HR, 2.22; 95\% Cl,1.12-4.38), APACHE II score $>21$ (HR, 1.82; 95\% $\mathrm{Cl}, 1.05-3.18)$, SOFA $\geq 8(\mathrm{HR}, 2.06 ; 95 \% \mathrm{Cl}, 1.12-3.81)$ and day7 NOX4 >18.2 ng/mL (HR, 2.17; 95\% $\mathrm{Cl}, 1.19-3.97)$ were independently associated with 28-day mortality. 


\section{Trend of NOX4 levels between day 1 and day 7according to weaning failure and 28-day mortality}

We analyzed the longitudinal trend of NOX4 level according to clinical outcomes in the study population (Figure 3).

In the failed extubation group, the baseline level of NOX4 significantly increased between day 1 and day 7

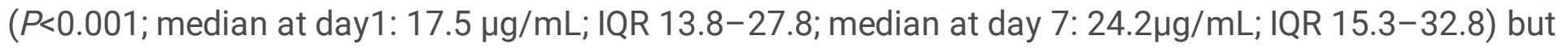
not in the successful extubation group $(P=0.081$; median at day1: $16.1 \mu \mathrm{g} / \mathrm{mL}$; IQR 12.4-23.3; median at day 7: $15.1 \mu \mathrm{g} / \mathrm{mL}$; IQR 12.2-20.8).

Similarly, in the 28-day death group, the level of NOX4 significantly increased between day 1 and day 7 (P = 0.001; median at day1: $18.1 \mu \mathrm{g} / \mathrm{mL}$; IQR 13.8-34.4; median at day 7: $25.2 \mu \mathrm{g} / \mathrm{mL}$; IQR 15.9-

41.7); however, this phenomenon was not observed in the 28-daysurvival group $(P=0.744$; median at day1: $16.4 \mu \mathrm{g} / \mathrm{mL}$; IQR 12.5-22.7; median at day 7: $16.4 \mu \mathrm{g} / \mathrm{mL}$; IQR 12.4-22.0).

\section{Discussion}

Our study suggeststhatNOX4 level may help predict successful weaning off from MV and 28-day mortality. Several indices have been used to predict successful extubation such as RSBI and maximal inspiratory pressure (MIP)[17-20]. However, the reported efficacy of these parameters for predicting successful extubation has been inconsistent; in addition, assessment of these indices requires a special device, which is a limitation[21-24].

McConville et al reported that improvement in the underlying disease process is superior to general rules regarding readiness for initiation of SBT[25]. Therefore, more objective measures are requiredto guide the recovery of underlying cause of respiratory failure and to predict the likelihood of extubation.

Among the Nox family, NOX4is upregulated in several pulmonary diseases including tuberculous fibrosis, idiopathic pulmonary fibrosis, and lung cancer $[26,27]$. Ling et al, reported significantly higher NOX4 levels in a rat model of ventilator-induced lung injury[28]. Biologically, NOX4 is believed to play a role in endothelial signal transduction, cytoskeletal reorganization, and apoptosis of endothelial cells[13, 29].

To the best of our knowledge, this is the first study that investigated plasma NOX4 levels in critically ill patients. Despite the complex biological mechanisms associated with NOX4, we found obvious clinical relevance of NOX4 levels in our patients.

In our study, lower NOX4 levels were associated with successful weaning off from MV within 3 weeks and NOX4 levels $>18.2 \mathrm{ng} / \mathrm{mL}$ on day 7 showed an independent association with extubation failure after adjusting for important clinical variables. 
The day 7 NOX4 level may assist in determining weaning readiness and help predict the duration of MV in intubated patients. In addition, the Kaplan-Meier survival curves and Cox-hazard proportional model supported the association between higher day 7 NOX4 level and 28-day mortality. A positive correlation was observed between plasma NOX4 level and the severity markers such as APACHE II score and SOFA score (APACHE II, $\square=0.220, P=0.003$; SOFA, $\square=0.316, P<0.001$ ). These results suggest a correlation of NOX4 level with systemic inflammation and disease severity. It is noteworthy that NOX4 was shown to play a distinct role in P.aeruginosa-mediated apoptosis and lung permeability in vivo and in vitro models[11].

In our study, prolonged duration of ventilation before extubation was a risk factor for extubation failure, which is consistent with the results reported by Lee et al[24]. We also found that SOFA score and APACHE II score were independently associated with extubation failure and 28-day mortality. A multicenter study conducted in surgical ICUs reported that SOFA score was a risk factor of extubation failure[30]. The previous studies showed that APACHE II scoring system predicted early weaning as well as mortality[31, 32]. Matic et al. reported that an APACHE II score of $<20$ indicated greater success in weaning the patient from the ventilator, which is consistent with our result[33]. However, in some studies, APACHE II failed to predict successful weaning from MV[34, 35]. The discrepancy between studies may be explained by heterogeneity with respect to subjects and the size of the study population.

Consistent with our results, previous studies have also shown that malignancy is a significant risk factor for in-hospital mortality in patients receiving MV support[36, 37].

As shown in Figure 3, we observed that NOX4 levels were not significantly different between the failed extubation group and the successful extubation group at initial assessment, but the difference between the two groups was particularly marked at day 7 due to increasing trend in the failed extubation group. Interestingly, similar results wereobserved between survivors and nonsurvivors. Follow up of NOX4 levels to identify trends may help predict the clinical outcomes in intubated patients.

Use of NOX4 level as a prognostic biomarker may be more accurate because it is significantly related to both weaning outcome and mortality. This study is the first clinical study that employed human blood samples to evaluate the relationship between plasma NOX4 level and clinical outcomes including weaning failure and 28-day mortality.

However, some limitations of our study should be considered while interpreting the results. First, this study was conducted at a single university-affiliated hospital and the study population was relatively small. Therefore, further validation is required before our results can be generalized to other clinical settings. Second, measurement of NOX4 level was done at day 1 and day 7of ICU admission. However, analysis at multiple time points may be required to determine the most appropriate measurement timepoint to predict clinical outcomes. Third, in vitro experimental data to support the potential prognostic utility of plasma NOX4 level is lacking. The exact underlying mechanism by which NOX4 activation contributes to extubation failure and mortality needs to be explored in further studies. 


\section{Conclusion}

In this study, higher day 7 plasma NOX4 level was significantly associated with weaning failure and 28day mortality among intubated patients. Serial measurements of plasma NOX4 level may help predict the clinical outcomes. In addition, plasma NOX4 level may be a potential therapeutic target in patients with MV.

\section{List Of Abbreviations}

NOX4: Nicotinamide adenine dinucleotide phosphateoxidase, ROS: reactive oxygen species, APACHE: Acute Physiology and Chronic Health Evaluation, SBT: spontaneous breathing test, PEEP: positive endexpiratory pressure, SOFA: Sequential Organ Failure Assessment, GCS: Glasgow Coma Scale, RSBI: rapid shallow breathing index

\section{Declarations}

\section{Acknowledgements}

Not applicable.

\section{Author contributions}

Conceptualization, JY Hong; Methodology and data collection, SY Park and Y Hong; Formal analysis and Investigation, Y Hong and SJ Woo; Writing-Original draft preparation, JY Hong; Writing-Review \& Editing,Y Kim and JJ Lee; Funding Acquisition: JY Hong

\section{Funding}

This research was supported by the Bio \& Medical Technology Development Program of the National Research Foundation (NRF)funded by the Korean government (MSIT) (NRF-2017M3A9E8033225) and was supported by the National Research Foundation of Korea Grant funded by Korean Government (NRF 2017R1C1B5017879). This research was supported by Hallym University Research Fund. The funders had no role in study design, data collection and interpretation or preparation of the manuscript.

\section{Availability of data and material}


The datasets used or analyzed during the current study are available from the current study are available from the corresponding author on reasonable request.

\section{Ethics approval and consent to participate}

The study was approved by the local ethics committee(IRB number: 2017-47)and informed consent was obtained from each participant.

\section{Consent for publication}

Not applicable

\section{Declaration of Conflicting interests}

The authors declare that they have no conflicts of interest with respect to research, authorship and publication of this article.

\section{References}

1.Mancebo J: Weaning from mechanical ventilation. Eur Respir J 1996, 9(9):1923-1931.

2.Seymour CW, Martinez A, Christie JD, Fuchs BD: The outcome of extubation failure in a community hospital intensive care unit: a cohort study. Crit Care 2004, 8(5):R322-327.

3.Cook DJ, Walter SD, Cook RJ, Griffith LE, Guyatt GH, Leasa D, Jaeschke RZ, Brun-Buisson C: Incidence of and risk factors for ventilator-associated pneumonia in critically ill patients. Ann Intern Med 1998, 129(6):433-440.

4.De Jonghe B, Bastuji-Garin S, Durand MC, Malissin I, Rodrigues P, Cerf C, Outin H, Sharshar T, Groupe de Reflexion et d'Etude des Neuromyopathies en R: Respiratory weakness is associated with limb weakness and delayed weaning in critical illness. Crit Care Med 2007, 35(9):2007-2015.

5.Jubran A: Critical illness and mechanical ventilation: effects on the diaphragm. Respir Care 2006, 51(9):1054-1061; discussion 1062-1054.

6.Lessard MR, Brochard LJ: Weaning from ventilatory support. Clin Chest Med 1996, 17(3):475-489.

7.Aboussouan LS, Lattin CD, Anne VV: Determinants of time-to-weaning in a specialized respiratory care unit. Chest 2005, 128(5):3117-3126. 
8.Esteban A, Alia I, Tobin MJ, Gil A, Gordo F, Vallverdu I, Blanch L, Bonet A, Vazquez A, de Pablo R et al: Effect of spontaneous breathing trial duration on outcome of attempts to discontinue mechanical ventilation. Spanish Lung Failure Collaborative Group. Am J Respir Crit Care Med 1999, 159(2):512-518.

9.Esteban A, Alia I, Gordo F, Fernandez R, Solsona JF, Vallverdu I, Macias S, Allegue JM, Blanco J, Carriedo $\mathrm{D}$ et al: Extubation outcome after spontaneous breathing trials with T-tube or pressure support ventilation. The Spanish Lung Failure Collaborative Group. Am J Respir Crit Care Med 1997, 156(2 Pt 1):459-465.

10.Bernard K, Hecker L, Luckhardt TR, Cheng G, Thannickal VJ: NADPH oxidases in lung health and disease. Antioxid Redox Signal 2014, 20(17):2838-2853.

11.Fu P, Mohan V, Mansoor S, Tiruppathi C, Sadikot RT, Natarajan V: Role of nicotinamide adenine dinucleotide phosphate-reduced oxidase proteins in Pseudomonas aeruginosa-induced lung inflammation and permeability. Am J Respir Cell Mol Biol 2013, 48(4):477-488.

12.Petrof BJ: Diaphragm Weakness in the Critically III: Basic Mechanisms Reveal Therapeutic Opportunities. Chest 2018, 154(6):1395-1403.

13.Pendyala S, Gorshkova IA, Usatyuk PV, He D, Pennathur A, Lambeth JD, Thannickal VJ, Natarajan V: Role of Nox4 and Nox2 in hyperoxia-induced reactive oxygen species generation and migration of human lung endothelial cells. Antioxid Redox Signal 2009, 11(4):747-764.

14.Supinski G, Stofan D, Nethery D, Szweda L, DiMarco A: Apocynin improves diaphragmatic function after endotoxin administration. J Appl Physiol (1985) 1999, 87(2):776-782.

15.Javeshghani D, Magder SA, Barreiro E, Quinn MT, Hussain SN: Molecular characterization of a superoxide-generating NAD(P)H oxidase in the ventilatory muscles. Am J Respir Crit Care Med 2002, 165(3):412-418.

16.Moro-Sibilot D, Aubert A, Diab S, Lantuejoul S, Fourneret P, Brambilla E, Brambilla C, Brichon PY: Comorbidities and Charlson score in resected stage I nonsmall cell lung cancer. Eur Respir J 2005, 26(3):480-486.

17.Capdevila XJ, Perrigault PF, Perey PJ, Roustan JP, d'Athis F: Occlusion pressure and its ratio to maximum inspiratory pressure are useful predictors for successful extubation following T-piece weaning trial. Chest 1995, 108(2):482-489.

18.Epstein SK: Etiology of extubation failure and the predictive value of the rapid shallow breathing index. Am J Respir Crit Care Med 1995, 152(2):545-549.

19.Kulkarni AP, Agarwal V: Extubation failure in intensive care unit: predictors and management. Indian J Crit Care Med 2008, 12(1):1-9. 
20.Mergoni M, Costa A, Primavera S, Salvadori A, Saccani A, Zuccoli P: [Assessment of various new predictive parameters of the outcome of mechanical ventilation weaning]. Minerva Anestesiol 1996, 62(5):153-164.

21.Salam A, Tilluckdharry L, Amoateng-Adjepong Y, Manthous CA: Neurologic status, cough, secretions and extubation outcomes. Intensive Care Med 2004, 30(7):1334-1339.

22.Uusaro A, Chittock DR, Russell JA, Walley KR: Stress test and gastric-arterial PCO2 measurement improve prediction of successful extubation. Crit Care Med 2000, 28(7):2313-2319.

23.Del Rosario N, Sassoon CS, Chetty KG, Gruer SE, Mahutte CK: Breathing pattern during acute respiratory failure and recovery. Eur Respir J 1997, 10(11):2560-2565.

24.Lee KH, Hui KP, Chan TB, Tan WC, Lim TK: Rapid shallow breathing (frequency-tidal volume ratio) did not predict extubation outcome. Chest 1994, 105(2):540-543.

25.McConville JF, Kress JP: Weaning patients from the ventilator. N Engl J Med 2012, 367(23):22332239.

26.Kim Y, Park SY, Jung H, Noh YS, Lee JJ, Hong JY: Inhibition of NADPH Oxidase 4 (NOX4) Signaling Attenuates Tuberculous Pleural Fibrosis. J Clin Med 2019, 8(1).

27.Amara N, Goven D, Prost F, Muloway R, Crestani B, Boczkowski J: NOX4/NADPH oxidase expression is increased in pulmonary fibroblasts from patients with idiopathic pulmonary fibrosis and mediates TGFbeta 1-induced fibroblast differentiation into myofibroblasts. Thorax 2010, 65(8):733-738.

28.Ling X, Lou A, Li Y, Yang R, Ning Z, Li X: [Losartan regulates oxidative stress via caveolin-1 and NOX4 in mice with ventilator-induced lung injury]. Nan Fang Yi Ke Da Xue Xue Bao 2015, 35(12):1739-1744.

29.Hu T, Ramachandrarao SP, Siva S, Valancius C, Zhu Y, Mahadev K, Toh I, Goldstein BJ, Woolkalis M, Sharma K: Reactive oxygen species production via NADPH oxidase mediates TGF-beta-induced cytoskeletal alterations in endothelial cells. Am J Physiol Renal Physiol 2005, 289(4):F816-825.

30.Buppha P, Kusumaphanyo C, Chittawatanarat K: Outcomes and Risk Factors of Extubation Failure: A Multicenter Study of the THAI Surgical Intensive Care Units (SICUs). J Med Assoc Thai 2016, 99 Suppl 6:S136-S144.

31.Dehghani A, Abdeyazdan G, Davaridolatabadi E: An Overview of the Predictor Standard Tools for Patient Weaning from Mechanical Ventilation. Electron Physician 2016, 8(2):1955-1963.

32.Carpene N, Vagheggini G, Panait E, Gabbrielli L, Ambrosino N: A proposal of a new model for long-term weaning: respiratory intensive care unit and weaning center. Respir Med 2010, 104(10):1505-1511. 
33.Matic I, Titlic M, Dikanovic M, Jurjevic M, Jukic I, Tonkic A: Effects of APACHE I/ score on mechanical ventilation; prediction and outcome. Acta Anaesthesiol Belg 2007, 58(3):177-183.

34.Rojek-Jarmula A, Hombach R, Krzych LJ: APACHE II score cannot predict successful weaning from prolonged mechanical ventilation. Chron Respir Dis 2017, 14(3):270-275.

35.Sanabria A, Gomez X, Vega V, Dominguez LC, Osorio C: Prediction of prolonged mechanical ventilation in patients in the intensive care unit A cohort study. Colomb Med (Cali) 2013, 44(3):184-188.

36.Shih CY, Hung MC, Lu HM, Chen L, Huang SJ, Wang JD: Incidence, life expectancy and prognostic factors in cancer patients under prolonged mechanical ventilation: a nationwide analysis of 5,138 cases during 1998-2007. Crit Care 2013, 17(4):R144.

37.Keng LT, Chung KP, Lin SY, Liang SK, Cheng JC, Chen IC, Chen YF, Chang HT, Hsu CL, Jerng JS et al: Significant Clinical Factors Associated with Long-term Mortality in Critical Cancer Patients Requiring Prolonged Mechanical Ventilation. Sci Rep 2017, 7(1):2148.

\section{Tables}

Table 1. Demographics and baseline characteristics of the study population 


\begin{tabular}{|c|c|c|c|}
\hline & $\begin{array}{l}\text { Failed extubation } \\
\qquad(\mathrm{n}=87)\end{array}$ & $\begin{array}{c}\text { Successful } \\
\text { Extubation } \\
(\mathrm{n}=97)\end{array}$ & $P$ \\
\hline Age§ & $76(66,83)$ & $69(57,78)$ & 0.003 \\
\hline Male $^{\dagger}$ & 66 (75.9) & $66(68)$ & 0.255 \\
\hline \multicolumn{4}{|l|}{ Severity } \\
\hline APACHE score ${ }^{\pi}$ & $23(20,28)$ & $19(15,23)$ & $<0.001$ \\
\hline SOFA score ${ }^{\pi}$ & $9(7,12)$ & $6(5,9)$ & $<0.001$ \\
\hline \multicolumn{4}{|l|}{ Comorbidity $^{\dagger}$} \\
\hline ESRD & $5(5.7)$ & $2(2.1)$ & 0.258 \\
\hline Heart failure & $16(18.4)$ & $15(15.5)$ & 0.694 \\
\hline Diabetes mellitus & $31(35.6)$ & $27(27.8)$ & 0.27 \\
\hline Cancer & $13(14.9)$ & $6(6.2)$ & 0.057 \\
\hline Hypertension & $40(46.0)$ & $47(48.5)$ & 0.769 \\
\hline A-fib & $13(14.9)$ & $14(14.4)$ & 0.998 \\
\hline COPD & $9(10.3)$ & $12(12.4)$ & 0.817 \\
\hline Liver cirrhosis & $4(4.6)$ & $6(6.2)$ & 0.751 \\
\hline Stroke & $16(18.4)$ & $13(13.4)$ & 0.42 \\
\hline $\begin{array}{l}\text { Intracerebral } \\
\text { hemorrhage }\end{array}$ & $5(5.7)$ & $9(9.3)$ & 0.416 \\
\hline $\begin{array}{l}\text { Charlson comorbidity } \\
\text { index }\end{array}$ & $2(1,3)$ & $2(1,3)$ & 0.225 \\
\hline Cause of intubation $^{\dagger}$ & & & 0.504 \\
\hline Cardiac arrest & $7(8.0)$ & $7(7.2)$ & \\
\hline Neurosurgery & $15(17.2)$ & $20(20.6)$ & \\
\hline Stroke & $0(0)$ & $2(2.1)$ & \\
\hline Operation & $1(1.1)$ & $4(4.1)$ & \\
\hline Respiratory & $62(71.3)$ & $63(64.9)$ & \\
\hline Sepsis & $2(2.3)$ & $1(1.0)$ & \\
\hline Pneumonia $^{\dagger}$ & $72(82.8)$ & $77(79.4)$ & 0.579 \\
\hline CURB-65 ${ }^{\square}$ & $3(2,4)$ & $2(2,3)$ & 0.001 \\
\hline $\mathrm{PaO} 2 / \mathrm{FiO} 2$ & $196.7(137.5,313.3)$ & $260(178.5,375)$ & 0.013 \\
\hline GCS ${ }^{\pi}$ & $6(5,10)$ & $9(6,11)$ & 0.001 \\
\hline
\end{tabular}




\begin{tabular}{|c|c|c|c|}
\hline 28-day mortality ${ }^{\dagger}$ & $59(67.8)$ & $2(2.1)$ & $<0.001$ \\
\hline ICU mortality $^{\dagger}$ & $72(82.8)$ & $6(6.2)$ & $<0.001$ \\
\hline MV duration" & $15(9,26)$ & $8(7,15)$ & $<0.001$ \\
\hline Crp (mg/dL) & $116.8(41.6,180)$ & $\begin{array}{c}69.6 \\
(11.4,184.9)\end{array}$ & 0.061 \\
\hline RSBI ๆ & $73(60,83)$ & $62(49,73)$ & $<0.001$ \\
\hline $\begin{array}{l}\text { Day } 1 \text { plasma NOX4 level } \\
\text { (ng/mL) }\end{array}$ & $17.5(13.8,27.8)$ & $16.1(12.4,23.3)$ & 0.061 \\
\hline $\begin{array}{l}\text { Day } 1 \text { NOX4 level > } 16.9 \\
\mathrm{ng} / \mathrm{mL} \dagger\end{array}$ & $48(55.2)$ & $44(45.4)$ & 0.237 \\
\hline $\begin{array}{l}\text { Day } 7 \text { plasma NOX4 level } \\
\text { (ng/mL) }\end{array}$ & $24.2(15.3,32.8)$ & $15.2(12.1,21.2)$ & $<0.001$ \\
\hline $\begin{array}{l}\text { Day } 7 \text { NOX4 level > } 18.2 \\
\text { ng/mL }+\end{array}$ & $58(66.7)$ & $35(36.1)$ & $<0.001$ \\
\hline
\end{tabular}

9 median (interquartile range)

tfrequency (\%)§ median (range)

૫ limited to patients with pneumonia

APACHE II: Acute Physiology, Age, Chronic Health Evaluation II, SOFA: Sequential Organ Failure Assessment, ESRD: end stage renal disease, GCS: Glasgow Coma Scale, ICU: intensive care unit, RSBI: rapid shallow breathing index

Table 2 Results of logistic regression model showing odds of weaning failure within 3 weeks $(n=184)$

\begin{tabular}{lcccc}
\hline & \multicolumn{2}{c}{ Univariate analysis } & \multicolumn{2}{c}{ Multivariate analysis } \\
& OR $(95 \% \mathrm{CI})$ & $P$ value & OR $(95 \% \mathrm{CI})$ & $P$ value \\
\hline RSBI $\geq 67$ & $2.51(1.38,4.58)$ & 0.003 & $2.05(0.97,4.30)$ & 0.059 \\
\hline Age $\geq 75$ years & $2.28(1.26,4.13)$ & 0.006 & $1.47(0.72,2.99)$ & 0.288 \\
\hline APACHE score $>21$ & $3.48(1.89,6.40)$ & $<0.001$ & $2.16(1.03,4.52)$ & 0.042 \\
SOFA $\geq 8$ & $4.69(2.52,8.74)$ & $<0.001$ & $2.66(1.26,5.59)$ & 0.01 \\
\hline MV days $>11$ & $2.77(1.53,5.04)$ & 0.001 & $3.36(1.62,6.99)$ & 0.001 \\
\hline Day 7 NOX4 level $>18.2 \mathrm{ng} / \mathrm{mL}$ & $3.54(1.93,6.51)$ & $<0.001$ & $3.13(1.49,6.57)$ & 0.003 \\
\hline
\end{tabular}


RSBI: rapid shallow breathing index, APACHE, Acute Physiology and Chronic Health

Evaluation II; SOFA: Sequential Organ Failure Assessment; MV, mechanical ventilation;

NOX4, NADPH oxidase 4; OR, odds ratio; CI, confidence interval

Table 3 Results of Cox regression analysis for survival prediction in intubated patients $(\mathrm{n}=184)$

\begin{tabular}{lccc}
\hline \multicolumn{1}{c}{ Variable } & Hazard ratio & $95 \%$ CI & $P$ \\
\hline Cancer & 2.22 & $1.12,4.38$ & 0.022 \\
\hline Age $\geq$ 75 years & 1.41 & $0.85,2.36$ & 0.187 \\
\hline APACHE score $>21$ & 1.82 & $1.05,3.18$ & 0.034 \\
\hline SOFA $\geq 8$ & 2.06 & $1.12,3.81$ & 0.021 \\
\hline Day 1 NOX4 level $>16.9 \mathrm{ng} / \mathrm{mL}$ & 0.94 & $0.53,1.64$ & 0.814 \\
Day 7 NOX4 level $>18.2 \mathrm{ng} / \mathrm{mL}$ & 2.17 & $1.19,3.97$ & 0.012 \\
\hline
\end{tabular}

APACHE, Acute Physiology and Chronic Health Evaluation II; SOFA: Sequential Organ Failure Assessment; NOX4, NADPH oxidase 4; CI, confidence interval

\section{Figures}
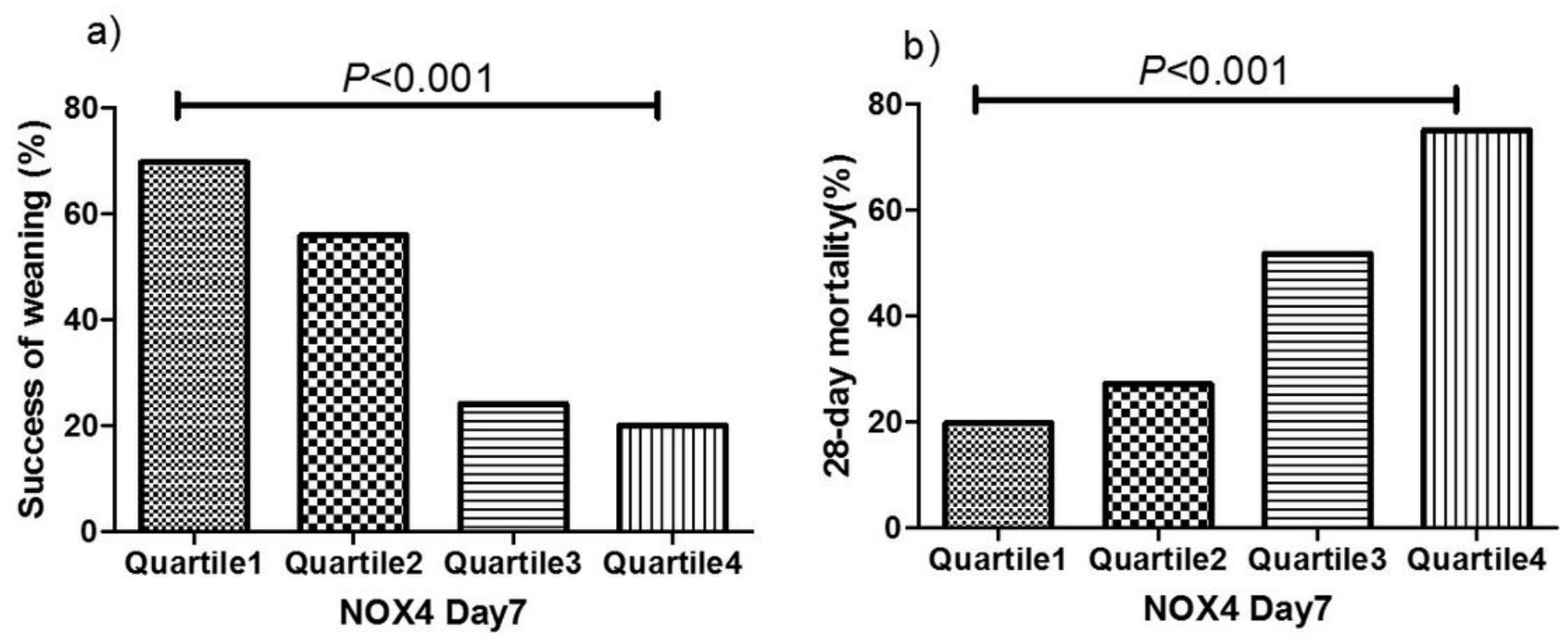

Figure 1 
(a) Success of weaning within 3 weeks according to day 7 NOX4 quartiles; (b) 28-day mortality according to day 7 NOX4 quartiles $(n=184)$ NOX4, NADPH oxidase 4

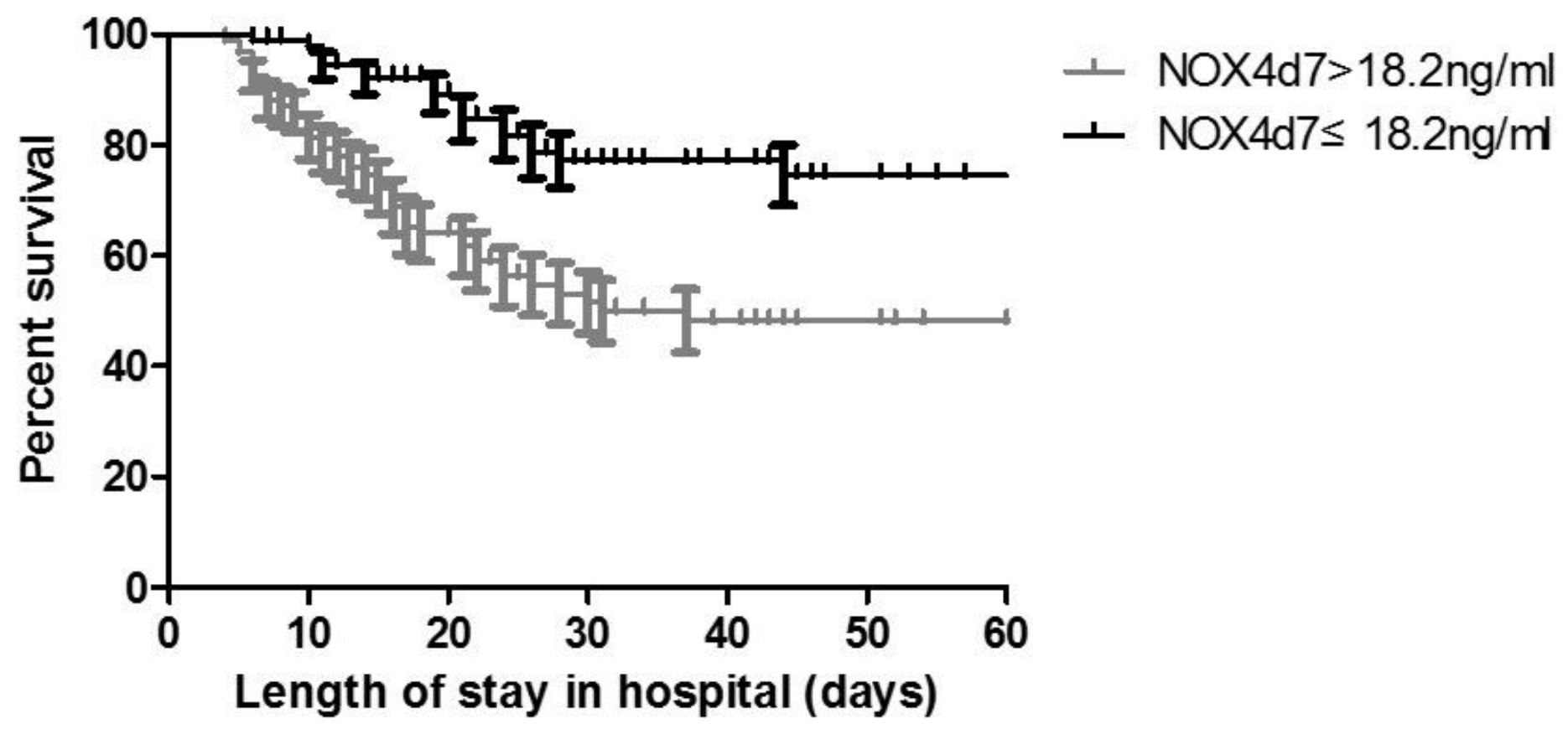

Figure 2

Kaplan-Meier survival curves in 28days according to day 7 NOX4 levels Kaplan-Meier survival analysis showed that the 28-day mortality of patients with plasma NOX4 level $\geq 18.2 \mathrm{ng} / \mathrm{mL}$ was higher than that of patients with plasma NOX4 level < $18.2 \mathrm{ng} / \mathrm{mL}$ NOX4, NADPH oxidase

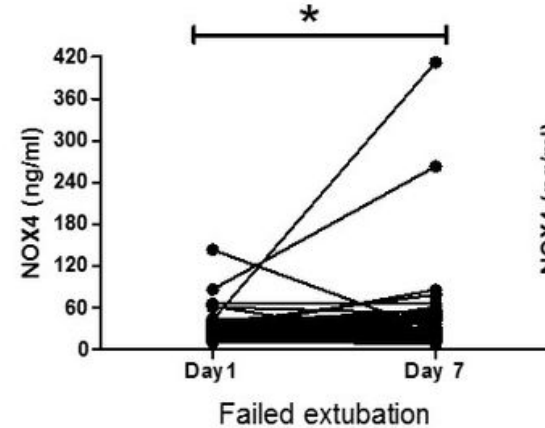

Failed extubation

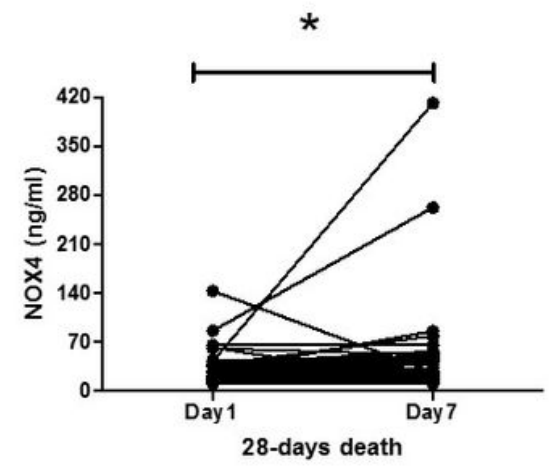

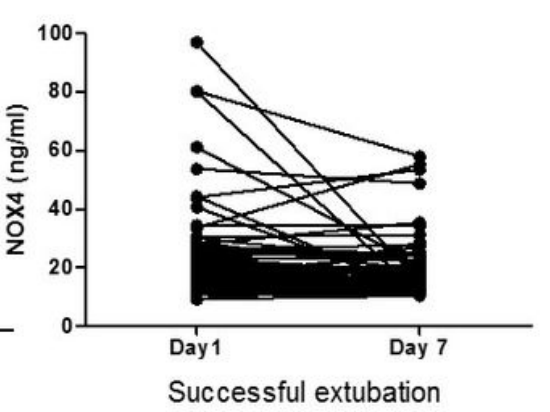
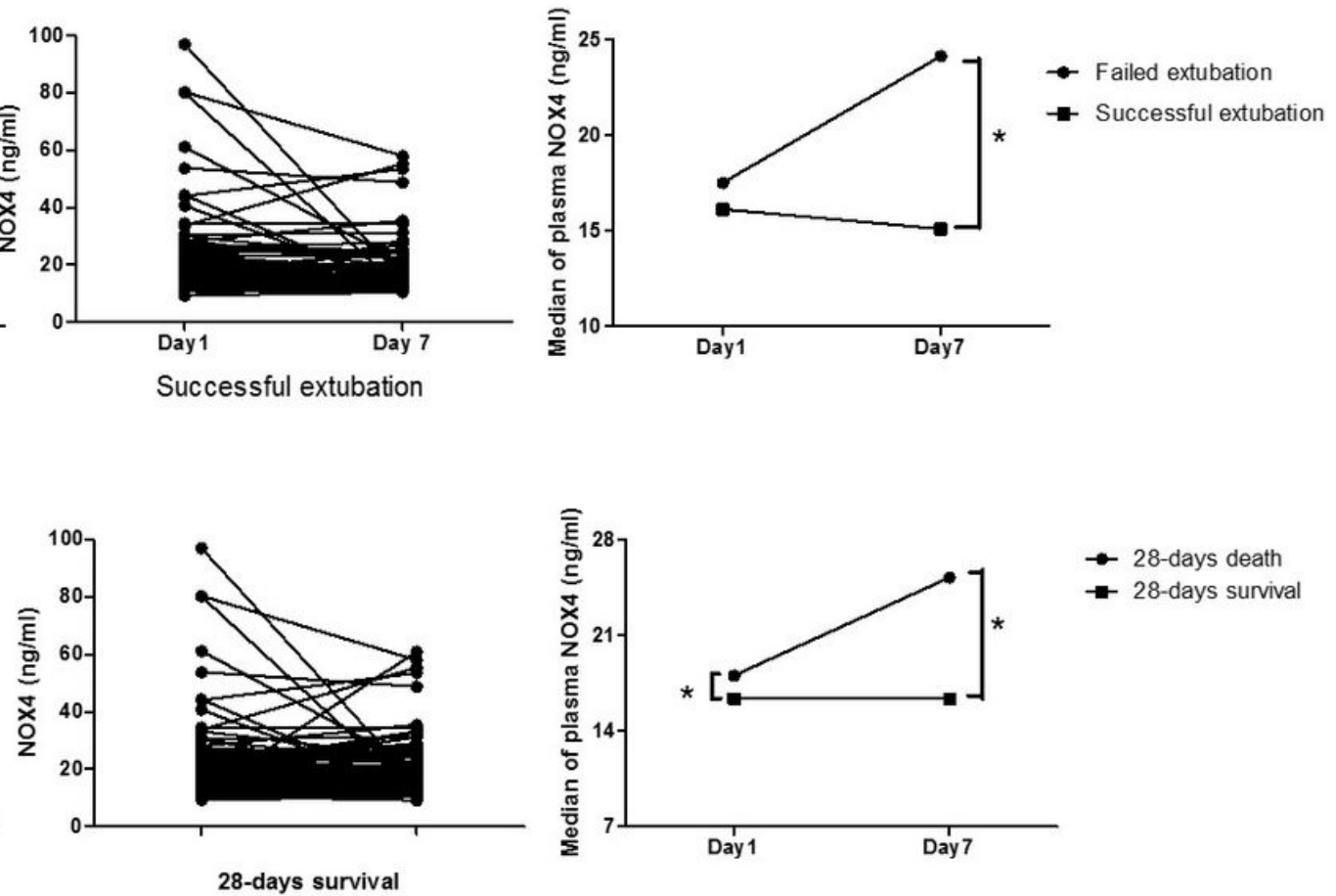


\section{Figure 3}

Longitudinal trend of plasma NOX4 level between day 1 and day 7 from start of mechanical ventilation according to weaning outcome (a) and 28-day mortality (b) NOX4, NADPH oxidase $4{ }^{*} \mathrm{P}<0.05$ 